DOI: $10.12731 / 2306-1561-2013-4-31$

\title{
APPROACH TO THE FORMATION OF PERSONNEL MANAGEMENT STRATEGY
}

\section{Prikhodko L.V.}

\begin{abstract}
Personnel policy defines the objectives associated with the attitude of the organization to the external environment (labor market, relationships with government agencies), as well as goals related to the ratio of the organization to its staff. Personnel policy of the organization - it is a complete personnel system that combines different forms of human resource management (strategy and tactics), the style of its holding in the organization and plans for the use of labor.
\end{abstract}

Keywords: staff, management, strategy, mergers model, evaluation of staff.

\section{ПОДХОД К ФОРМИРОВАНИЮ СТРАТЕГИИ УПРАВЛЕНИЯ ПЕРСОНАЛОМ}

\section{Приходько Л.В.}

\section{Аннотация}

Кадровая политика определяет иели, связанные с отношением организации к внешнему окружению (рынок труда, взаимоотномения $c$ государственными органами), а также цели, связанные с отношением организации к своему персоналу. Кадровая политика организащии - это целостная кадровая система, объединяюшая различные формы кадровой работы (стратегию и тактику), стиль ее проведения в организации и планы по использованию рабочей силь.

Ключевые слова: персонал, управление, стратегия, модель слияния, оценка персонала.

\section{Стратегии управления персоналом}

Стратегии управления персоналом направлены на поддержку достижения конкретных целей организации, определяют направление работы и содержат сроки и показатели, по которым может быть оценена эффективность их реализации.

В основе стратегии управления персоналом лежит стратегия развития организации. Стратегия управления персоналом всегда требует изменения производственного поведения и профессионализма.

Разработка стратегии управления персоналом начинается с сопоставления организационных компетенции, необходимых для реализации общей стратегии развития, и фактического состояния человеческих ресурсов организации и определение 
соответствия между ними (рисунок 1). Для стратегии управления человеческими ресурсами разрабатываются планы организационно-технических мероприятий (ОТМ).

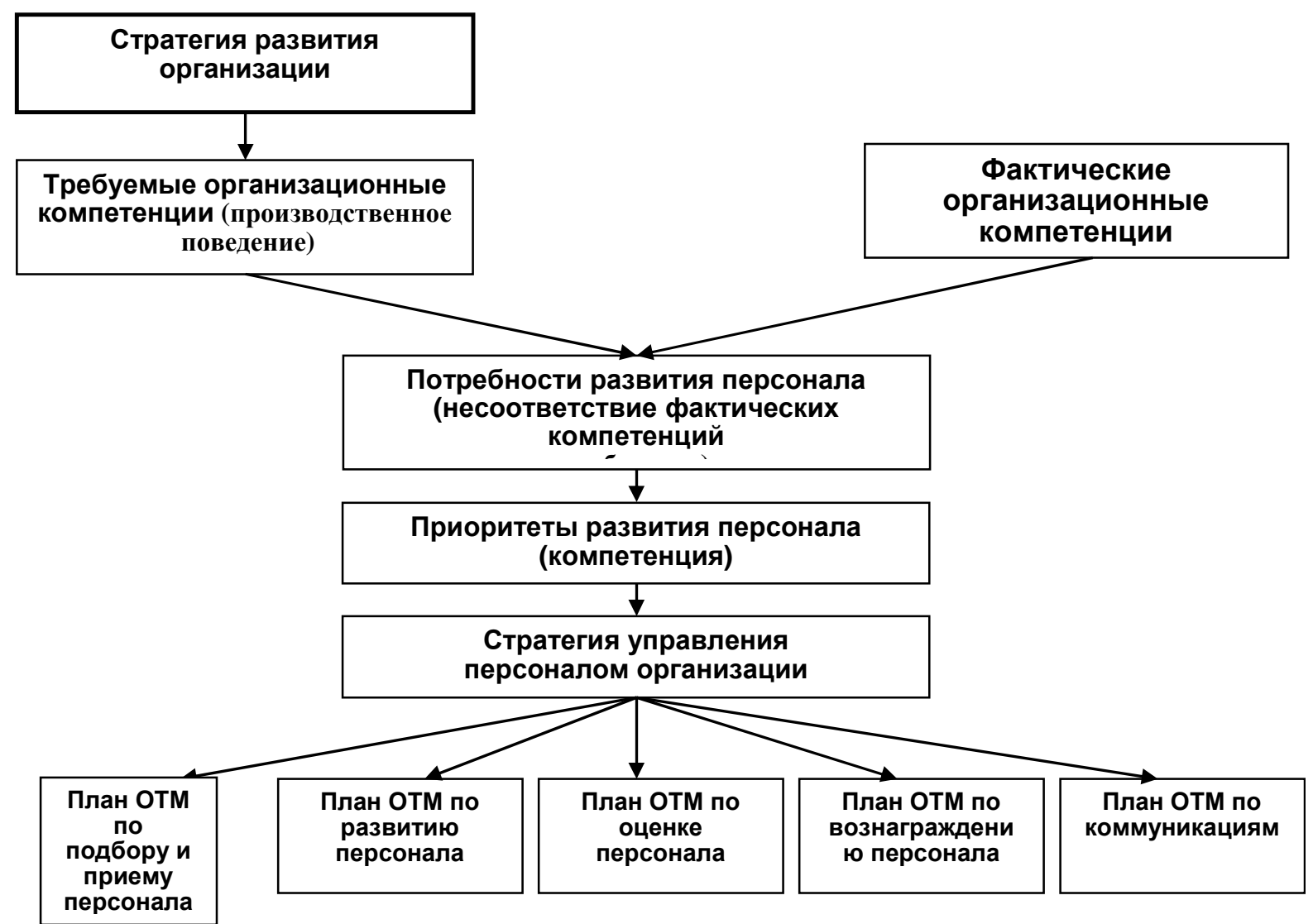

\section{Рисунок 1 - Схема формирования стратегии управления персоналом}

Кадровая политика должна увеличивать возможности организации, реагировать на изменяющиеся требования технологии и рынка в ближайшем будущем.

Основные аспекты кадровой стратегии и новые функции менеджмента персонала банка включают:

- поднятие престижа организации;

- исследование атмосферы внутри организации;

- анализ перспективы развития потенциалов рабочей силы;

- обобщение и предупреждение причин увольнения с работы.

Создание сплоченной, ответственной, высокоразвитой и высокопроизводительной рабочей силы (человеческого капитала или человеческих ресурсов) это не только создание благоприятных условий труда, обеспечение возможности продвижения по службе и необходимой степени уверенности в завтрашнем дне. Это и обеспечение в повседневной кадровой работе учета интересов всех категорий работников и социальных групп трудового коллектива. 
Задачи кадровой политики:

- заниматься планированием численности работников на предприятиях в соответствии со штатным расписанием;

- постоянно добиваться увеличения в составе персонала тех людей, кто обладает хорошими знаниями, и следить за тем, чтобы таких работников становилось все больше в каждом подразделении;

- проводить анализ факторов внешней среды, чтобы убедиться в том, что имеется предложение определенных профессий для комплектования личного состава такими служащими, каких еще нет в штате организации;

- разработка согласованной кадровой политики, включающей системы набора, подготовки, совершенствования и оплаты кадров;

- разработка политики отношений между администрацией и работниками;

- разработка конкретных программ использования трудовых ресурсов;

- коррекция отклонений от стратегического направления;

- наблюдения и контроль за выполнением стратегических и тактических программ.

Для реализации формирования одного отделения из двух необходим механизм слияния.

Во-первых, меняется организационная структура, создается новая управляющая команда, совершенствуется технологическая структура, сокращается излишний персонал.

Модель слияния может быть представлена следующим образом (рисунок 2).

В меньшей мере реорганизация должна коснуться технической подсистемы.

В большей мере усовершенствованию должна быть подвергнута социальная подсистема: менеджмент, как система и как персоналии, структура взаимодействия людей в организации, сложившаяся рабочая атмосфера.

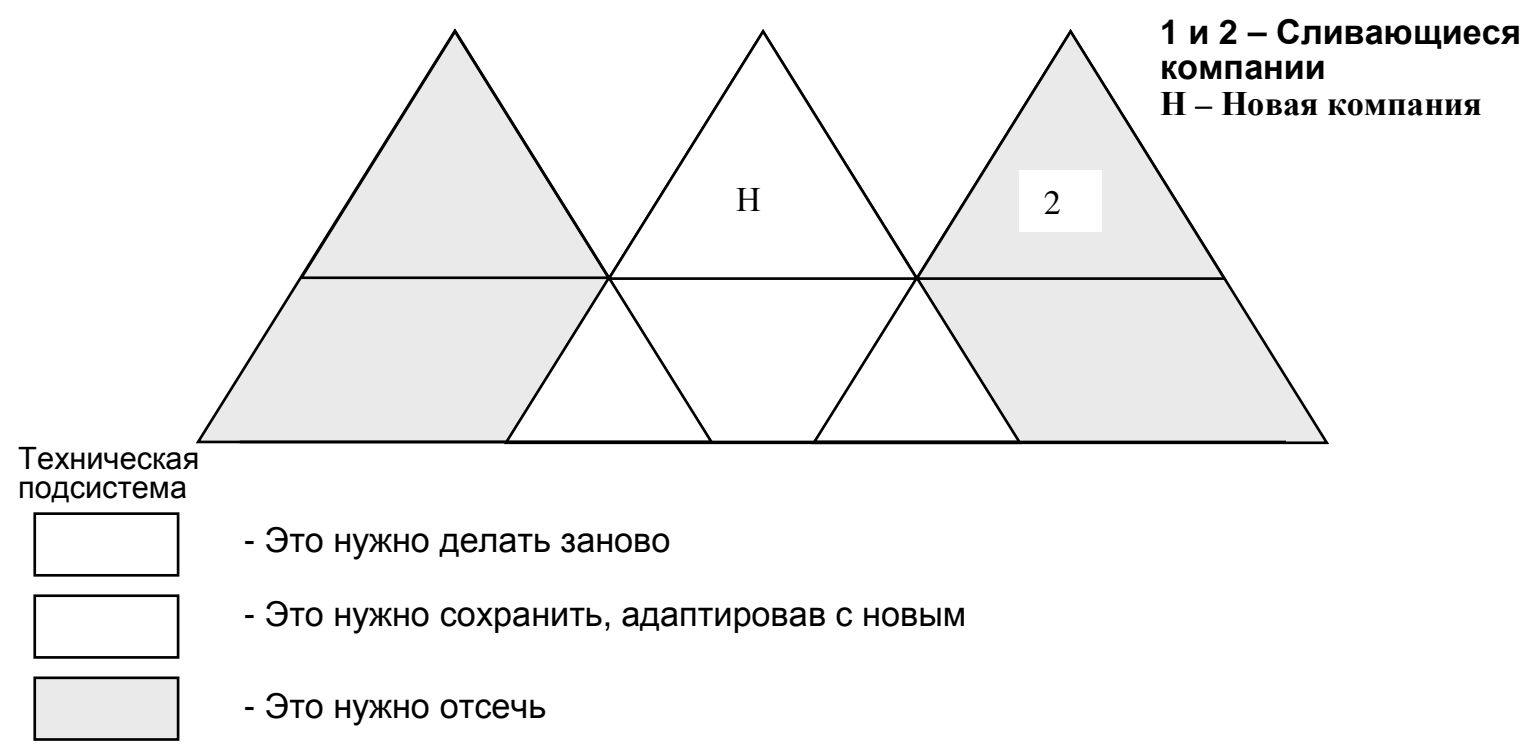

Рисунок 2 - Модель слияния 
Для того чтобы провести усовершенствование организации, необходимо проводить его одновременно в трех подсистемах, уделяя равное внимание развитию людей и совершенствованию процессов, протекающих в организации. Качественно подойти и выполнить работу по усовершенствованию организации можно с помощью матрицы движения к успеху.

\section{Новые механизмы и принципы отбора кадров}

Отбор кадров - это процесс изучения психологических и профессиональных качеств работника с целью установления его пригодности для выполнения обязанностей на определенном рабочем месте или должности и выбора из совокупности претендентов наиболее подходящего с учетом соответствия его квалификации, специальности, личных качеств и способностей, характеру деятельности, интересам организации и его самого.

Существует два подхода к установлению соответствия человека в организации. При первом подходе человек подбирается для выполнения определенной работы, осуществления определенной функции в организации. При втором подходе работа подбирается человеку таким образом, чтобы она лучше всего соответствовала его возможностям и отвечала его притязаниям на определенное место в организации. Первый подход является традиционным и наиболее распространенным в современной практике менеджмента. Второй подход также имеет практическую реализацию преимущественно для высокопоставленных чиновников или в рамках японского типа управления. Для большинства российских кредитных организаций характерно применение первого подхода к подбору людей для выполнения определенной работы или иными словами, включение человека в организацию.

\section{Методы оценки персонала}

Эффективная оценка персонала играет огромную роль в управлении им, являясь основой множества процедур: приема на работу, внутренних перемещений, увольнений, зачисление в состав резерва на выдвижение, материального и морального стимулирования, применения санкций, переподготовки и повышения квалификации, контроля персонала, совершенствования организации управленческого труда, приемов и методов работы, улучшение структуры аппарата. Отсутствие надежных систем оценки может привести к тому, что организация потеряет способного работника и приобретет неспособного.

Психологический ассессмент при подборе и расстановке работников - новая форма работы с управленческими кадрами. Особенностью данного метода является то, что он позволяет одновременно решить такие конкретные управленческие задачи, как выявление оптимальных кандидатур на руководящие должности, разработка рекомендаций по совершенствованию стиля руководства, снижение риска потери ценных работников, а также улучшение психологического климата.

Эффективность системы действия персонала непосредственно зависит и от самого структурного построения организации. Прежде всего, это касается: 
- разделение задач и обязанностей среди работников;

- распределение задач и сотрудников по подразделениям;

- определение вертикальных и горизонтальных информационных потоков и отношений сотрудничества;

- проведение мер по координации.

Оценка персонала во всех случаях должна осуществляться по принципу: «пригоден = надежен + способен», а в деловых характеристиках отражается информация: уровень надежности и лояльности; целесообразные направления использования; многофункциональность; ожидаемое поведение; обучаемость.

\section{Развитие персонала}

Необходимость развития персонала вызывается следующими причинами:

- увеличивающейся стоимостью персонала как производственного ресурса;

- конкуренцией, требующей сокращения затрат и более эффективного использования труда;

- технологическим прогрессом, требующим овладения новыми навыками и переподготовки работников;

- крупные объекты требуют новых навыков менеджмента для координации действий;

- подготовкой к занятию новой должности;

- социальной ответственностью организации за увеличение потенциала своих работников.

Цели повышения квалификации:

А) удержать, уберечь, сохранить работника;

Б) создание резерва в сфере управления, а значит продвижение по служебной лестнице;

В) необходимость повышения производительности труда с одной стороны, и с другой стороны - повышение качества продукции, качества труда;

Г) поиск для работников тех работ, которые соответствуют их запросам, характеру, специальности.

Для адекватного определения потребностей профессионального развития каждая из участвующих в этом процессе сторон должна понимать, под воздействием каких факторов складываются потребности организации в развитии своего персонала. Этими факторами являются:

- динамика внешней среды (потребители, конкуренты, поставщики, государство);

- развитие техники и технологии, влекущее за собой появление новой продукции, услуг и методов производства;

- изменение стратегии развития организации;

- создание новой организационной структуры;

- освоение новых видов деятельности. 
Основная форма развития людей в организации - обучение и научение. Процессы обучения можно выполнять как на рабочем месте, так и вне рабочего места (Таблица $1)$.

\section{Таблица 1 - Процессы обучения}

\begin{tabular}{|c|c|}
\hline Обучение на рабочем месте & ге вне рабочего места \\
\hline $\begin{array}{l}\text { Копирование - работник прикрепляется к } \\
\text { специалисту, учится, копирует действия } \\
\text { этого человека. В старину это называли } \\
\text { «отдать в подмастерье». }\end{array}$ & $\begin{array}{l}\text { Деловые игры - коллективная игра } \\
\text { (обычно с компьютером), включая разбор } \\
\text { учебного примера, в ходе которого } \\
\text { участники игры получают роли в игровой } \\
\text { деловой ситуации и рассматривают } \\
\text { последствия принятых решений. }\end{array}$ \\
\hline $\begin{array}{l}\text { Наставничество - занятия менеджера со } \\
\text { своим персоналом в ходе ежедневной } \\
\text { работы. }\end{array}$ & \\
\hline $\begin{array}{l}\mid \text { Делегирование - передача сотрудникам } \\
\text { четко очерченной области задач } \\
\text { полномочиями принятия решения по } \\
\text { оговоренному кругу вопросов, при этом } \\
\text { менеджер обучает подчиненных в ходе } \\
\text { выполнения работы. }\end{array}$ & $\begin{array}{lllr}\text { Учебные ситуации } & - \text { реальная } & \text { или } \\
\text { выдуманная } & \text { управленческая } & \text { ситуация } \\
\text { вопросами } & \text { для анализа. При } & \text { этом } \\
\text { устраняются } & \text { жесткие } & \text { рамки } & \text { времени, } \\
\text { которые } & \text { сковывают } & \text { мысль } \\
\text { производственной обстановке. }\end{array}$ \\
\hline $\begin{array}{l}\text { Метод усложняющих заданий } \\
\text { специальная программа рабочих действий, } \\
\text { выстроенная по степени их важности, } \\
\text { расширения объема задания и повышения } \\
\text { сложности. Заключительная ступень - } \\
\text { самостоятельное выполнение задания. }\end{array}$ & $\begin{array}{l}\text { Моделирование - воспроизведение } \\
\text { реальных условий } \quad \text { работы } \\
\text { использование тренажеров, макетов и др.). }\end{array}$ \\
\hline $\begin{array}{l}\text { Ротация - работник переводится на новую } \\
\text { работу или должность для получения } \\
\text { дополнительной } \\
\text { квалификации и п расширения опыта. } \\
\text { Обычно на срок от нескольких дней до } \\
\text { нескольких месяцев. }\end{array}$ & $\begin{array}{l}\text { Tренинг сензитивности - участия в группе } \\
\text { с целью повышения человеческой } \\
\text { восприимчивости и улучшения умений } \\
\text { взаимодействовать с другими. Проводится } \\
\text { в присутствии психолога. }\end{array}$ \\
\hline 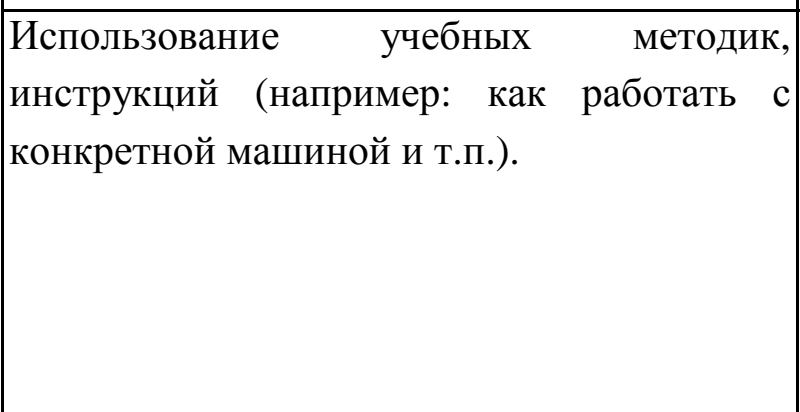 & 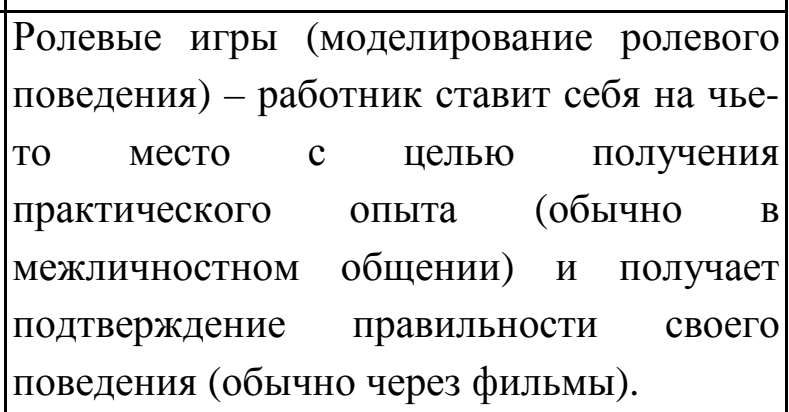 \\
\hline
\end{tabular}




\begin{tabular}{|c|c|}
\hline фирменного обучения: & Плюсы внеш \\
\hline 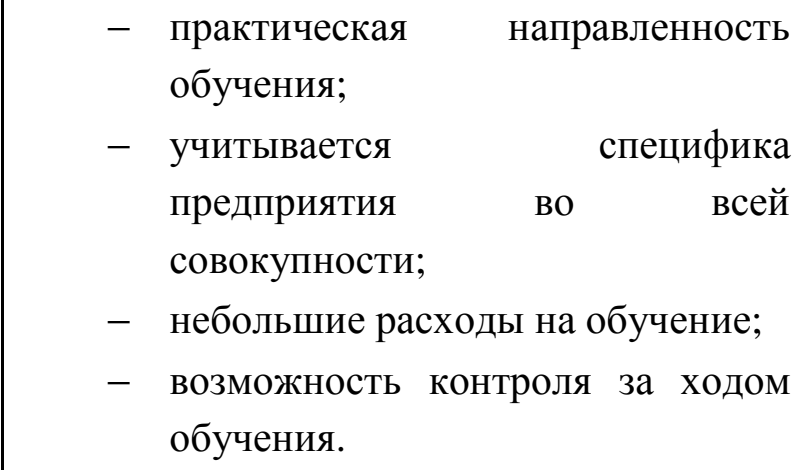 & 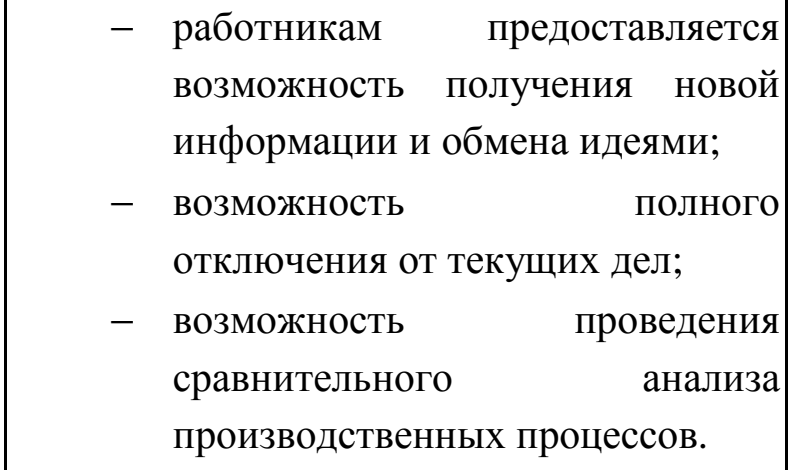 \\
\hline Минусы внутрифирменного обучения: & Минусы внешнего обучения: \\
\hline $\begin{array}{l}\text { - } \text { отсутствие обмена опытом и } \\
\text { информацией с работниками } \\
\text { других предприятий; } \\
\text { - отвлечение от обучения для } \\
\text { выполнения текущих дел. }\end{array}$ & $\begin{array}{l}\text { - } \text { меньшая практическая } \\
\text { направленность; } \\
\text { - } \text { в меньшей степени или вообще } \\
\text { не учитывается специфика; } \\
\text { - большие затраты; } \\
\text { - } \text { работники воспринимают это } \\
\text { обучение как дополнительный } \\
\text { отпуск. }\end{array}$ \\
\hline
\end{tabular}

\section{Заключение}

Одной из кадровых стратегий является создание системы непрерывного профессионального обучения персонала, формирование на ее основе кадрового потенциала, имеющего базовое финансовое или экономическое образование, с последующим его развитием посредством систематического повышения квалификации или профессиональной переподготовки.

Целью непрерывного профессионального обучения персонала является постоянное соответствие квалификации «профессиональных навыков каждого сотрудника банка квалификационным требованиям, предъявляемым к соответствующим категориям работников.

Успех непрерывного профессионального обучения работников банка во многом определяется качеством его планирования. Планирование непрерывного обучения персонала является составной частью разработки бизнес-плана банка, которое исходит из основных направлений стратегии банка и его потребностей в высококвалифицированных специалистах.

Исходя из конкретных заданий бизнес-плана банка, строится схема подготовки и переподготовки кадров.

В этой связи особую значимость приобретает процесс обучения работников, замещающих руководящие должности, либо состоящих в резерве на выдвижение.

На основе анализа потребности в обучении и увязки ее с приоритетными направлениями деятельности разрабатывается сводный план обучения, а также комплекс целевых программ обучения различных категорий персонала, 
ориентированных на обучение реализации стратегии в соответствии с приоритетными направлениями деятельности предприятия или организации.

Данная система позволяет обеспечить формирование и поддерживание базового уровня профессиональных знаний и навыков всех работников с минимальным отрывом от работы, а также осуществить отбор наиболее перспективных для подготовки универсальных специалистов филиалов и формирование резерва на руководящие должности.

\section{Список информационных источников}

[1] Баринов К.А. Опыт разработки и использования ролевых игр для подготовки и переподготовки специалистов предприятий промышленности и транспортного комплекса / К.А. Баринов, Д.А. Буров, А.В. Бугаев, А.В. Остроух // Научный вестник МГТУ ГА. - 2009. - №141. - С. 188-197.

[2] Дедов Д.Л. Технология интерактивного 3D-моделирования для разработки виртуальных тренажерных комплексов / А.В. Остроух, М.Н. Краснянский, С.В. Карпушкин, Д.Л. Дедов, А.А. Руднев // Дистанционное и виртуальное обучение. 2011. - №10. - С. 4-12.

[3] Краснянский М.Н. Интеграция виртуальных тренажеров в процесс обучения операторов технических систем с использованием Интернет-технологий / А.В. Остроух, М.Н. Краснянский, С.В. Карпушкин, Д.Л. Дедов // Дистанционное и виртуальное обучение. - 2010. - №7. - С. 66-70.

[4] Краснянский М.Н. Виртуальные тренажерные комплексы для обучения и тренинга персонала химических и машиностроительных производств / А.В. Остроух, М.Н. Краснянский, К.А. Баринов, Д.Л. Дедов, А.А. Руднев // Вестник ТГТУ. - 2011. - Т.17. - № 2. - С.497-501.

[5] Исмоилов М.И. Подготовка и переподготовка персонала предприятий промышленного и транспортного комплексов с применением мобильных технологий: Монография / М.И. Исмоилов, А.Б. Николаев, А.В. Остроух. - SaintLouis, MO, USA: Publishing House Science and Innovation Center, 2013. - 166 c. ISBN 978-0-615-67111-6.

[6] Остроух А.В. Реализация деловых игр в компьютерных системах обучения / К.А. Баринов, А.В. Остроух, Н.Е. Суркова // Открытое и дистанционное образование. Томск: ОАО «Издательство ТГУ», 2007. - №3 (27), - С. 28-33.

[7] Остроух А.В. Информационные технологии в научной и производственной деятельности / [ред. А.В. Остроух] - М: ООО "Техполиграфцентр", 2011. - 240 с. ISBN 978-5-94385-056-1.

[8] Остроух А.В. Структура автоматизированной информационной системы и алгоритм проектирования виртуальных тренажерных комплексов для обучения операторов нефтехимических производств / А.В. Остроух, М.Н. Краснянский, С.В. Карпушкин, Д.Л. Дедов, А.Б. Николаев // Вестник Харьковского национального автомобильно-дорожного университета. - Харьков: ХНАДУ, 2011. - Вып. 54. - С. 170-179.

[9] Остроух А.В. Постановка задачи проектирования виртуальных тренажерных комплексов для обучения операторов технических систем /А.В. Остроух, М.Н. Краснянский, С.В. Карпушкин, Д.Л. Дедов // Информационные технологии в проектировании и производстве. - 2012. - №2. - С. 46-50. 
[10] Остроух, А.В. Принцип разработки учебных материалов для автоматизированных систем подготовки персонала нефтехимических предприятий [Текст] / A.В. Остроух, А.М. Меркулов, П.А. Петриков, Ю.П. Бакатин // В мире научных открытий. Серия «Проблемы науки и образования». - 2012. - №2.6 (26). - С.184193.

[11] Остроух А.В. Автоматизация процесса подготовки персонала промышленных предприятий на основе интегрированной обучающей среды / А.В. Остроух, П.А. Петриков, Н.Е. Суркова, М.Н. Краснянский // Вестник Российского нового университета. Серия естествознание, математика, информатика. - 2012. - Вып. 4. C. 81-88.

[12] Чурин В.В. Использование компьютерных тренажеров для подготовки рабочих дорожно-строительных профессий / В.В. Чурин, А.В. Остроух, А.А. Подберёзкин // Молодой ученый. - 2011. - №4. Т.3. - С. 28-29.

[13] Чурин В.В. Сравнительный анализ компьютерных тренажеров для подготовки рабочих дорожно-строительных профессий / А.В. Остроух, В.В. Чурин // В мире научных открытий. - 2011. - №9 (21). - С.131-149.

[14] Krasnyansky M.N. Application of virtual simulators for training students of the chemical technology type and improvement of professional skills of chemical enterprises personnel / E.N. Malygin, M.N. Krasnyansky, S.V. Karpushkin, Y.V. Chaukin, A.V. Ostroukh // Вестник ТГТУ. - 2007. - Т.13. - №1Б. - C.233-238.

[15] Ostroukh A.V. Application of the module-competentive approach in the development of the electronic educational resources for E-learning system of professional education institution / K.A. Barinov, A.V. Ostroukh // Engeneering competencies -tradition and innovation. Proceedings of the 37th International IGIP Symposium, September 7-10, 2008, Moscow, Russia. - pp. 253-254. - ISBN 978-5-7962-0093-3. 